\title{
LiNGUAGEM, CONHECIMENTO E VERDADE nas Confissões de Agostinho
}

\author{
Ana Beatriz Gobbo de Brito Sousa*
}

\begin{abstract}
RESUMO
Na obra Confissões, Agostinho de Hipona apresenta um impasse quanto à veracidade de seu conhecimento a respeito de si e de Deus e suas palavras. 0 autor argumenta que, ao direcionar-se a Deus, sua fala não pode ser indevida, sendo preferível se calar do que falar algo incoerente. Como resposta a este impasse, ele recorre à primazia da interioridade, reconhecendo em Deus a única fonte reveladora de um conhecimento verdadeiro e o mestre interior capaz de guiá-lo a uma linguagem verdadeira. 0 presente trabalho busca, a partir das aporias levantadas no início dos livros I e X das Confissões, meditar sobre o caminho percorrido por Agostinho para buscar uma fala que seja verdadeira a respeito de Deus tendo a ciência de que seu conhecimento e sua linguagem são mediados, insuficientes, porém, mesmo assim são necessários. Para tanto, esta pesquisa se apoiou nas contribuições de Madureira (2017), Bermon (2019), Mammi (2000) e suas considerações à obra presentes no prefácio à edição brasileira (2017).
\end{abstract}

Palavras-chave: Agostinho; Confissões; linguagem; conhecimento; verdade

falta o título e o resumo em inglês.

* Universidade Federal do ABC. Estudante do curso de Bacharelado em Ciências e Humanidades pela Universidade Federal do ABC.

anabebrito@gmail.com

Revista Páginas de Filosofia, v. 9, n. 2, p. 121-129, jul.-dez. 2020 


\section{INTRODUÇÃO}

A linguagem, para além de seu sentido semântico, gramatical, lógico, é um elemento que constitui nossa subjetividade e acompanha o processo de conhecimento. É a linguagem também que atua na descrição da realidade, tendo sua importância em maior ou menor grau para apontar-nos o que é verdadeiro. Conhecer, portanto, o que está ao nosso redor e o que se encontra interno a nós é um procedimento intermediado pela linguagem, e em sua obra Confissões $(2017)^{1}$, Agostinho levantará os impasses na busca do conhecimento de si e de Deus e a possibilidade de uma fala verdadeira.

Agostinho já introduz seus escritos reconhecendo o abismo existente entre o homem e seu criador; o primeiro como simples fragmento de uma criação e condicionado ao estado de pecador; o segundo como um ser grandioso, louvável e pleno em sabedoria. Esta oposição será latente em toda a obra das Confissões, demarcando a diferença significativa entre a capacidade de conhecimento humano e divino, e a possibilidade de uma fala verdadeira diante do que é conhecido.

Na sequência desta temática, no capítulo X, o pensador descreve seu desejo de conhecer a Deus tal como ele é conhecido, isto é, de forma plena. Para tanto, ele pede e espera que sua alma pertença a Deus, pois este ama a verdade e é a própria fonte de esclarecimento. Confessar-se, portanto, será uma prática da verdade internamente (à Deus em seu coração) e externamente por seus escritos (aos leitores das Confissões) ${ }^{2}$.

Nesse processo de conhecimento, o autor cai em um ponto de limitação do seu discurso ao reconhecer a falibilidade da palavra ao

1 Tradução em português de Lorenzo Mammì (2017). As referências às Confissões apresentam o título da obra abreviado (Conf.), seguido do número do livro, capítulo e parágrafo do texto.

2 Que eu te conheça, meu conhecedor, que eu te conheça como sou conhecido. Virtude da minha alma, entra nela e captura-a, para que a tenhas e possuas, sem mancha nem ruga. Esta é minha esperança, por isso falo e daquela esperança gozo, quando gozo saudavelmente. 0 resto da vida é tão menos deplorável, quanto mais o deploramos, e tanto mais deplorável, quanto menos o deploramos. Com efeito, eis que amas a verdade, porque quem a pratica vem à luz. Quero praticá-la diante de ti em meu coração pela confissão, e diante de muitas testemunhas pelos meus escritos. (Conf., X, 1, 1) 
tentar referir-se a Deus. Ele argumenta que esta fala não pode ser indevida, sendo preferível calar-se do que falar algo incoerente. Mas então o que seria falar a respeito Deus?

0 presente trabalho busca meditar, com base no início dos livros I e X das Confissões, sobre a insuficiência da linguagem para verbalizar o que ocorre na interioridade humana, mas também ao se referir ao divino, reconhecendo sua presença no processo de conhecimento de si e de Deus, e como essa fala poderia trazer algo de verdadeiro visto sua limitação. Para tanto, traçou-se o seguinte aporte teórico: Bermon (2019), Madureira (2017), Mammi (2000) e seu prefácio à edição brasileira da obra Confissões (2017).

\section{CONHECER PARA INVOCAR, OU INVOCAR PARA CONHECER?}

Logo no início das Confissões, após demarcar a diferença entre o homem e seu criador, Agostinho argumenta que há uma inquietação no homem, incitada pelo próprio Deus, que o leva a louvá-lo. Porém esse louvor só é possível após invocá-lo, e logo o autor se vê num impasse: é necessário primeiramente conhecer ou invocar a Deus? Há uma necessidade de conhecimento prévio, mesmo que incerto a respeito de Deus, pois caso contrário, como saber que não se invoca uma outra coisa? A busca para que se conheça a Deus se dará, portanto, invocando-o, com a fé que lhe foi dada pelo próprio Deus, e nesse processo de busca contínua será exercitado seu louvor.

O filósofo prossegue questionando o sentido de o termo invocar, e como comentário sobre a mesma passagem Bermon explica "que é preciso ter em mente que Agostinho joga com a etimologia de "invoca$r e$ ", que é formado a partir de "vocare in", literalmente "chamar dentro"” (BERMON, 2019, p. 121). O autor nesse ponto questiona como Deus poderia tornar-se espacial e ser chamado para dentro do homem? Como este sendo onipresente estaria contido em suas criaturas? Deus estaria contido em tudo o que se apresenta na realidade?

A resposta dada pelo autor no final do segundo parágrafo nos conduz a compreensão de que o homem não poderia existir se não estivesse já em Deus, o qual seria o fundamento e o meio no qual tudo é. Por que então invocá-lo se o homem já está em Deus? Agostinho parece 
não se propor a responder propriamente o porquê visto que já partiu da inquietação humana diante de seu criador, então seus passos seguintes serão em descrever o tipo de fala que se apresenta diante de Deus.

\section{II.O CONHECIMENTO HUMANO E A LINGUAGEM}

Para o objetivo deste trabalho decidimos traçar um paralelo entre dois momentos na obra das Confissões: no primeiro a vontade de louvar a Deus é o que faz o autor ultrapassar as aporias que irá encontrar no livro I, e no segundo, a partir do livro X, em que a felicidade terá o mesmo papel. Em ambos os momentos há uma similaridade dos assuntos tratados em que Agostinho inicia sua fala relatando a insuficiência do conhecimento humano sobre Deus, sendo no fundo um desconhecimento, e a nudez humana diante da onisciência divina. Como o homem, portanto poderia conhecer e falar a respeito deste Ser infinito em atributos e impassível de ser contido na interioridade humana?

No livro X, após ter iniciado sua fala com uma invocação, um desejo de conhecimento sobre Deus, o autor constata no decorrer de sua fala que seu conhecimento é incompleto:

$\mathrm{Tu}$, com efeito, me julgas, Senhor, porque, ainda que ninguém conheça o homem, dentre os homens, senão o espírito do homem, que está nele, contudo há algo do homem que nem o espírito do homem que está nele sabe, mas tu, Senhor, que o fizeste, sabes tudo dele. Eu, porém, embora me rebaixe diante de ti e me considere terra e cinza, todavia sei algo de ti, que não sei de mim. Certamente, vemos em espelho e por enigma, não ainda face a face (Conf., $X, 5,7$ ).

Comentando o texto acima, Madureira expõe que há "dois tipos de conhecimento: (1) o conhecimento no presente estado da vida (agora) e mediado (por espelho); (2) o conhecimento no futuro estado da vida (depois) e direto, não mediado (face a face) " (MADUREIRA, 2017, p. 33). 0 conhecimento de Deus será sempre completo e direto, enquanto o conhecimento humano utilizará ferramentas que possam intermediar o sujeito e aquilo que se pretende conhecer, seja a si mesmo ou a Deus.

Em suma, a incompletude do conhecimento, na concepção agostiniana, dá-se pela experiência humana atravessada por duas condições 
temporais qualitativamente diferentes. Esta ideia se refere às influências dos escritos paulinos presente na primeira carta aos Coríntios: "Hoje vemos como por um espelho, confusamente; mas então veremos face a face. Hoje conheço em parte; mas então conhecerei totalmente, como eu sou conhecido." ${ }^{3}$.

Esta experiência da insuficiência ocorre de maneira semelhante com o discurso pois a cada expressão Agostinho reconhece a insuficiência de sua linguagem e o quão ela se torna imprecisa quanto mais se distancia do divino. No prefácio às Confissões, Mammi relata que em Agostinho "a fala surge como expressão imprecisa, porque [é] mediada por convenções, dos desejos interiores, com o fim de impô-los aos outros". A linguagem retrata a interioridade de maneira deturpada pois visa a dominação, e através da instrução é manipulada apenas para fins práticos, criando-se assim "um hábito linguístico que encobre e deforma a alma que deveria revelar" (MAMMI, 2017, p. 16).

Qual seria, portanto, a postura adequada do sujeito diante de seu desejo de conhecer e de falar sobre Deus?

Em ambos o homem deve se colocar como ouvinte e reconhecer Deus como a condição de possibilidade de um conhecimento e de uma fala verdadeira. Apenas Deus conhece o homem de forma inesgotável e a si mesmo, podendo relevar-se à humanidade e descrever quem ela é, pois "se ouvirem de ti sobre eles mesmos, não poderão dizer "O Senhor mente". Com efeito, o que é ouvir de ti sobre si, senão se conhecer" (Conf., X, 3, 3). Quanto à linguagem, o mestre interior, que é o Deus encarnado, é quem conduz o homem interior a uma fala mais apurada e em concordância com a verdade, noção mais desenvolvida e defendida na obra De magistro:

No que diz respeito a todas as coisas que compreendemos, não consultamos a voz de quem fala, a qual soa de fora, mas a verdade que dentro de nós preside à própria mente, incitados talvez pela palavra a consultá-la. Quem é consultado ensina verdadeiramente, e este é Cristo, que habita, como foi dito, no interior do homem" (De Magistro, XI, 38, p. 395)

3 Referência ao texto da carta de I Corintios 13:12

Revista Páginas de Filosofia, v. 9, n. 2, p. 121-129, jul.-dez. 2020 
Porém, o filósofo expõe que sua fala só é possível pois é dirigida ao divino, diante dEle (coram deo), como bem explica Bermon "a confissão é uma palavra verdadeira de um tipo singular: ela somente é possível na medida em que é formulada consciente e explicitamente diante de Deus, o qual é reconhecido como fonte de toda verdade" (BERMON, 2019, p. 117)

Quando a palavra encontra seu limite e concebe os paradoxos ante o divino (transcendente e imanente; amoroso e irado; tão longe e tão perto), é nesse momento que está se voltando a uma linguagem máxima uma vez que reconhece sua insuficiência e debilidade. Agostinho assume que não se deve falar de forma incoerente com o que se diz. Sendo assim, ao se referir a Deus a fala humana seria falível, mas mesmo assim não poderia ser calada. Mas o que seria falar a respeito de Deus? Um diálogo necessário, uma relação a partir de elogios (júbilos) e por isso as diversas menções nas Confissões a textos dos salmos. Quanto a isso, Mammi comenta:

Agostinho, ao contrário, considera a linguagem um instrumento tanto mais limitado quanto mais o conteúdo a ser expresso é de natureza espiritual. Há conteúdos grandes demais para caber na linguagem humana. Nesse caso, é necessário recorrer ao jubilus, não porque este expresse aqueles conteúdos, mas porque o canto sem palavras é símbolo de nossa incapacidade para nomear Deus e, ao mesmo tempo, testemunho de que somos permeados pela palavra divina, junto com a Criação inteira. Compreender o jubilus da terra inteira significa deixar-se falar pela Palavra da Criação, renunciando a nomeá-la (MAMMI, 2000, p. 10).

Tanto para o conhecimento quanto ao se referir a linguagem, Agostinho irá optar pela via da interioridade. Ao voltar sua atenção para si ele compreende que o homem interior é aquele que pode conhecer, sendo descrito como aquele capaz de discernir o que provém do exterior:

Mas o interior é melhor. Com efeito, é a ele que se referiam todos os mensageiros corporais, como a um supervisor e juiz das respostas do céu e da terra e de tudo o que está neles, quando diziam: "Não somos Deus" e "Ele nos fez". O homem interior conhece isso pela ação do exterior; eu, o interior, conheci essas coisas, eu, eu alma, pelos sentidos do meu corpo. (Conf., X, 9) 
Agostinho encontra no próprio Deus a fonte de possibilidade do conhecimento e da linguagem apurada, porém a linguagem terá de despir-se de suas interferências para se chegar a uma Palavra Absoluta. Como descrito por Mammi:

Para inverter esse processo de alienação progressiva, é necessário, segundo Agostinho, pôr-se à escuta da fonte de onde brota a fala: a palavra mental, o pensamento no ato de se verbalizar, o verbum mentis - e deste remontar à Palavra absoluta, o Verbo divino que ilumina a mente e permite a intuição imediata, eterna e universal das verdades últimas" (2017, p.16).

Reconhecendo a limitação de seu conhecimento e de sua linguagem, faz-se necessário ao ser humano abrir os ouvidos do coração para que Deus se revele a ele, como um mestre interior, pois é na alma onde o homem pode ouvir o divino. Agostinho, portanto, traz a centralidade da palavra divina e situa que é em seu coração que esta palavra será ouvida: dize-me pelos teus atos de misericórdia, Senhor meu Deus, o que és para mim. Dize à minha alma: eu sou tua salvação. Dize-o, para que eu ouça. Eis diante de ti os ouvidos do meu coração (Conf., I,5,5).

\section{CONSIDERAÇões FINAIS}

Agostinho reconhece seus limites quanto criatura diante de seu Criador. Porém não permite que seus impasses o impeçam a dirigir-lhe os pensamentos e palavras. É em seu homem interior onde Deus será buscado, uma vez que é aí onde já se encontra. Ele encontra no próprio Deus a fonte de possibilidade do conhecimento e da linguagem apurada. Para isso ele recorre à primazia da interioridade, reconhecendo em Deus a única fonte reveladora de um conhecimento verdadeiro e o mestre interior capaz de guiá-lo a uma linguagem verdadeira. Sua fala só é possível pois é dirigida ao divino, diante dEle (coram deo).

Há algo no homem que lhe é incognoscível até para o mais profundo do seu ser - seu espírito - sendo conhecido apenas por Deus. Porém, mesmo reconhecendo sua insignificância diante do divino, há algo em Deus que podemos conhecer de maneira incompleta, por "enigma”, por "espelho", isto é, através de algo intermediário. Tudo o que diz respeito 
a esse "eu" só pode ser dito devido a iluminação divina. Sendo assim, Agostinho quer, portanto, confessar-se quanto ao que já lhe foi esclarecido sobre si mesmo assim como o que ainda não foi.

Reconhecendo a limitação de seu conhecimento e de sua linguagem, faz-se necessário ao ser humano abrir os ouvidos do coração para que Deus se revele a ele, como um mestre interior. É um movimento de pôr-se a escuta diante daquele que é a única fonte da palavra verdadeira. Quanto a seu discurso, Agostinho expõe que sua fala é feita por meio das "palavras da alma e o clamor dos pensamentos", demonstrando que a simples linguagem não é o local exato de expressão do que está contido nas Confissões. As palavras seriam como ruídos que o silenciam, sendo que aquilo que quer expressar está mais profundo ligado aos sentimentos. Como bem exposto por Mammi: A única fala que não é silêncio é a que fala de Deus. A única coisa que vale a pena dizer é o que não pode ser dito ${ }^{4}$.

\section{REFERÊNCIAS}

AGOSTINHO DE HIPONA. Confissões. Tradução Lorenzo Mammi. São Paulo: Companhia das Letras, 2017.

AGOSTINHO DE HIPONA. De magistro. Tradução de Ângelo Ricci. São Paulo: Abril Cultural, 1980. Disponível em <https://s3.amazonaws.com/padrepauloricardo-files/ uploads/46lhr78fnn3y7wsqve42/0sPensadores-SantoAgostinho.pdf $>$. Acesso em 20 de Abril, 2019.

BERMON, Emmanuel. As aporias das confissões agostinianas. Revista Ética e Filosofia Política, v. 2, n. 21,p. 115-128, jan. 2019. Disponível em: <https://eticaefilosofia.ufjf. emnuvens.com.br/eticaefilosofia/article/view/262>. Acesso em: 16 de Abril 2019.

MADUREIRA, Jonas. Conhecer-te, ó conhecedor de mim!. In:__ Inteligência Humilhada. São Paulo, Vida Nova, 2017.

MAMMI, Lorenzo. Canticum Novum: música sem palavras e palavras sem som no pensamento de Santo Agostinho. Estudos Avançados, São Paulo , v. 14, n. 38, p. 347-366, 2000. Disponível em <http://www.scielo.br/scielo.php?script=sci_arttext\&pid=S0103-40142000000100020\&lng=en\&nrm=iso >. Acesso em 20 de Abril, 2019.

4 Prefácio a Confissões, p.20

Revista Páginas de Filosofia, v. 9, n. 2, p. 121-129, jul.-dez. 2020 
